\title{
Physical activity intention and attendance behaviour in Finnish youth with cerebral palsy - results from a physical activity intervention: an application of the theory of planned behaviour
}

\author{
Alfredo Ruiz', ${ }^{1}$, Kwok Ng ${ }^{2,3}$, Pauli Rintala', Kaisa Kaseva4 ${ }^{4}$, Taija Finni' \\ ${ }^{1}$ Faculty of Sport and Health Sciences, University of Jyväskylä, Nokia, Finland \\ ${ }^{2}$ School of Educational Sciences and Psychology, University of Eastern Finland, Joensuu and Kuopio, Finland \\ ${ }^{3}$ Department of Physical Education and Sport Sciences, University of Limerick, Ireland, Joensuu, Finland \\ ${ }^{4}$ Cicero Learning, Faculty of Educational Sciences, University of Helsinki, Helsinki, Finland
}

Physical activity is associated with better health in individuals with cerebral palsy (CP). Numerous physical activity interventions have been designed to promote physical activity among youth with CP. No previous studies have explored the factors contributing to the intention to participate and predicting attendance behaviour for these interventions. Using theory of planned behaviour (TPB), this study explored the prediction of physical activity intention and attendance behaviour in a physical activity intervention aiming to promote physical activity in a sample of young individuals with CP. Males with CP aged 9-21 years were asked to complete measures of attitude, subjective norms, perceived behavioural control and, intentions towards a physical activity intervention. Participants had no cognitive impairments to understand and follow instruc- tions, were categorised into Gross Motor Function Classification System I-III, did not receive any specific lower limbs' medical treatment, or did not participate in a strength training program for lower limbs within 6 months before the study. Subjective norms were found to be the only significant predictor of intention, accounting for $83 \%$ of variance in intention. Intention and perceived behaviour control were found to be a nonsignificant predictor of attendance behaviour in youth with CP. The results show that TPB is a relevant tool in the prediction of intention towards a physical activity intervention in Finnish youth with CP.

Keywords: Exercise, Intention, Motor skills disorders, Motivation, Patient compliance, Attitude to health

\section{INTRODUCTION}

Cerebral palsy (CP) refers to a group of impairments characterized by the affection of posture and movement. $\mathrm{CP}$ is reported as the most common physical impairment in childhood (Oskoui et al., 2013). The prevalence in Europe is 2.08 per 1,000 live births (Johnson, 2002). Physical activity is generally recognized as enhancing physical and mental health (Biddle et al., 2019). Physical activity is defined as any body movement produced by skeletal muscles that requires energy expenditure (Caspersen et al., 1985). Physical activity participation for individuals with $\mathrm{CP}$ has been associated with better health (Damiano, 2006; Fowler et al., 2007; Kolehmainen et al., 2011; Ryan et al., 2014; Verschuren et al., 2014; Wright et al., 2019), with social and emotional well-being (Wright et al., 2019), and good quality of life (Chen et al., 2005; Wang et al., 2008).

For youth with $\mathrm{CP}$, the focus of the research during last two decades has been on increasing physical activity participation (Novak et al., 2013; Stribling and Christy, 2017; Verschuren et al., 2014). With the aim at promoting physical activity, a large number of studies have been presented resulting in a growing list of physical activity interventions (Fowler et al., 2007). Despite the wide range
${ }^{*}$ Corresponding author: Alfredo Ruiz (i) https://orcid.org/0000-0002-6655-1919 Faculty of Sport and Health Sciences, PO Box 35, FI-40014 University of Jyväskylä, Nokia, Finland

Email: alfredo.a.ruiz-egea@student.jyu.fi

Received: August 11, 2021 / Accepted: October 19, 2021
This is an Open Access article distributed under the terms of the Creative Commons Attribution Non-Commercial License (https://creativecommons.org/licenses/by-nc/4.0/) which permits unrestricted non-commercial use, distribution, and reproduction in any medium, provided the original work is properly cited. 
of studies, no previous studies had investigated the motivational factors influencing participation and attendance to these physical activity interventions. The motivational factors may determine the results of the interventions and they could have an impact on ensuring the benefits of the interventions (Wallace et al., 2014). In addition, a better understanding of those motivational factors based on an appropriate theoretical framework may inform future interventions aiming to promote sustained physical activity (Wallace et al., 2014). This could be of a great significance since the promotion of sustained behaviour postintervention is an unresolved issue (de Araújo et al., 2020; Novak et al., 2013; Verschuren et al., 2014).

As a theoretical framework, this study uses the theory of planned behaviour (TPB) (Ajzen, 1991) to understand the motivational factors contributing participation in a physical activity intervention and, to predict attendance behaviour in Finnish youth with $\mathrm{CP}$. Attendance is understood as the number of sessions attended out of the actual number of sessions offered (Hawley-Hague et al., 2016). According to the TPB, the most important predictor of people behaviour is their behavioural intention (Ajzen, 1991). Three factors influence intention: (a) the attitude which is based on a person's positive or negative evaluation of outcomes of the behaviour, i.e. an expectancy-value interaction; (b) the subjective norms $(\mathrm{SN})$ that are the perceived pressure one is experiencing from significant others to perform the behaviour (Ajzen, 1991; Ajzen and Driver, 1991). The third factor is the person's belief about whether they will succeed in the behaviour or not and the degree of control over external factors, which is known as perceived behavioural control (PBC) (Ajzen, 1991). Attitude, SN, and PBC are reliable predictors of intention in health behaviour accounting for $40 \%-50 \%$. of variance in meta analytic reviews (Armitage and Conner, 2001). Similarly, the relationship between intention and behaviour has been shown in meta-analyses, explaining between $20 \%-40 \%$ of the variance in health behaviours (Bélanger-Gravel et al., 2013).

Based on the TBP, this study explores the motivational factors influencing intention and predicting attendance behaviour to a physical activity intervention. Previous studies have found support for the TPB in exploring factors involved in behavioural intention among typically developed youth in physical activity interventions (Darabi et al., 2017). Further, TPB has been widely used in understanding factors involved in behavioural intention for example, in studies on social behaviour (Hsu et al., 2017; Verma and Chandra, 2018; Zhang et al., 2017), consumer behaviour (Scalco et al., 2017) or health behaviour (Chevance et al., 2017). In addition, previous literature has supported the validity of the TPB, and has shown the influence of attitude, SN, and PBC on intention towards physical activity in typically developed population (e.g., Neipp et al., 2013). Fig. 1 shows the hypothesized relationships between the TPB factors. The assessment of intention is recommended when predicting volitional behaviour (Netemeyer et al., 1991). Further, individuals with higher levels of intention to enrol in a behaviour are more likely to enact such behaviour

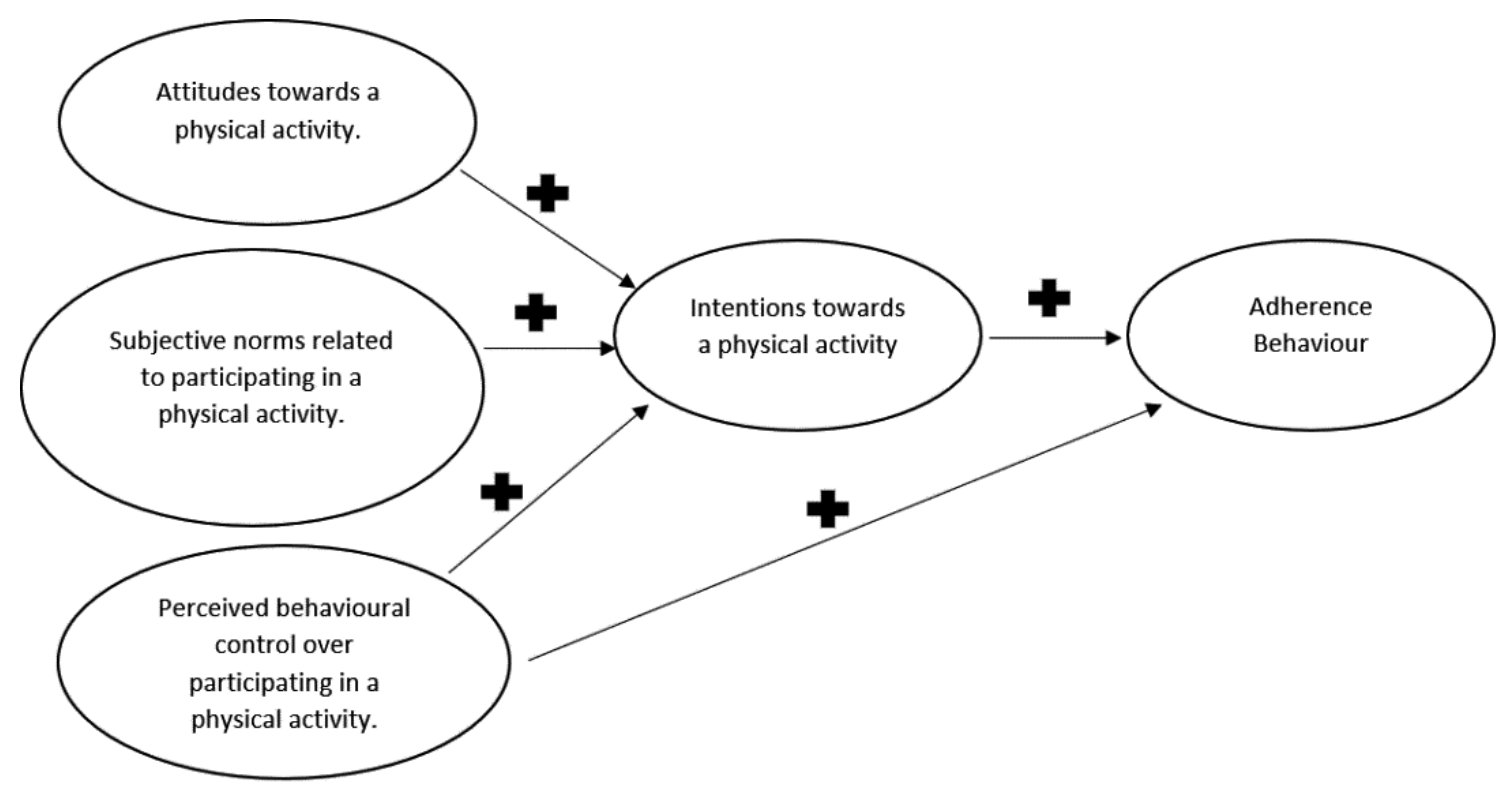

Fig. 1. Hypothesized theoretical model (Ajzen, 1991). 
(Hagger et al., 2002). Moreover, TPB has been widely used in predicting attendance in health behaviour (e.g., Drossaert et al., 2003; Mulholland and Van Wersch, 2007). The large support of previous research makes the TPB an empirically validated theoretical framework for understanding intention and predicting attendance behaviour towards physical activity. To our knowledge, no previous studies have explored the TPB factors in youth with $\mathrm{CP}$ as participants in a physical activity intervention.

This paper reports the results of a survey that used TPB in an attempt to explain intention and predict attendance behaviour in a physical activity intervention for Finnish youth with CP. The survey contained items assessing the main elements of the TPB. The aim was to explore the extent to which the theory affords prediction of intention and attendance behaviour in Finnish youth with $\mathrm{CP}$. A second aim was to explore the strength of the associations between attitude, $\mathrm{SN}$, and $\mathrm{PBC}$ on intention and attendance behaviour (Fig. 1). Finally, the study explored the reliability of the items used to assess attitude, SN, PBC, and intention in Finnish youth with CP.

\section{MATERIALS AND METHODS}

Our research study included a physical activity intervention that consisted of two to three $(90 \mathrm{~min}$ ) sessions per week for 12 weeks including strength, flexibility, and gait training. The exercise for CP intervention (EXECP intervention) explored the effects of a tailored exercise therapy intervention on physical capacity and function, neuromuscular mechanisms, and cardiometabolic risk factors of children and young adults with CP (for further details see Valadao et al., 2021). The EXECP intervention replicated previous interventions promoting physical activity (Verschuren et al., 2014). Ethical approval was obtained from Central Finland Hospital District ethics committee (04/2017). A sample of participants were collected through a wide variety of $\mathrm{CP}$ associations, physiotherapy clinics, hospitals, or direct advertisements including the distribution of pamphlets at the university facilities or in social media (Facebook). A total of 18 children and young adults agreed to participate and full set of data for the purpose of this study was obtained from 13 males aged 9-21 years (mean \pm standard deviation, $14.70 \pm 4.86$ ). Participants were invited to join a familiarization phase and informed of the aims of the study. In these initial sessions, participants were introduced to the research team, facilities, and instruments that were used later during the intervention phase. During this familiarization phase, a survey based on TPB was distributed. Participants were instructed to complete the sur- vey at home by themselves on a paper-form questionnaire. Upon completion of the survey, participants returned it to the research team during the following session. The exercise intervention took place approximately 3 months after the familiarization phase.

The following inclusion criteria were adopted in this study: Participants' age between 9-24 years, diagnosed with spastic hemiplegia or diplegia-type CP and classified as level I to III in the Gross Motor Function Classification System (GMFCS; Palisano et al., 1997). Exclusion criteria were any of the following treatments during the 6 months prior to the study: lower limbs surgery, intrathecal baclofen and botulinum toxin, selective dorsal rhizotomy, or serial casting on the lower limbs. In addition, participants were excluded if they were part of a strength training program for lower limbs within 6 months previous to the study. Cognitive impairment limiting the ability to understand and follow instructions during the study was an exclusion criterion. Finally, participants unable to stand with both heels in contact with the ground were excluded.

\section{TPB measures}

\section{Attitude towards a physically active behaviour}

Two 7-point bipolar adjective scales were used to assess attitude towards a physically active behaviour. The items were: (a) For me to participate in this physical activity intervention on a regular basis is: 1 extremely pleasant -7 extremely unpleasant; and (b) For me to attend this physical activity intervention on a regular basis is: 1 interesting -7 boring. The mean of the responses to the two items was used to measure participants' attitude towards the physical activity intervention.

\section{SN with respect to a physically active behaviour}

The mean values to the two items were used as a measure of $\mathrm{SN}$. The items of a 7-point bipolar scale were: (a) It is expected of me that I attend this physical activity intervention on a regular basis: 1 definitely true - 7 definitely false; and (b) Most people whose opinions I value approve of my attending this physical activity intervention on a regular basis: 1 strongly agree -7 strongly disagree.

\section{PBC over the physical activity intervention}

The mean values over the two items were used to measure PBC with a 7-point scale. The items were: (a) Whether or not I attend this physical activity intervention on a regular basis is completely up to me: 1 strongly agree - 7 strongly disagree; and (b) I am confident that if I wanted to I could attend this physical activity intervention on a regular basis: 1 definitely true -7 definitely false. 


\section{Intention to engage in the physical activity}

The mean values over the two items were used to measure intention towards the physical activity intervention with a 7-point scale. The items were: (a) I plan to attend this physical activity intervention on a regular basis: 1 extremely likely - 7 extremely unlikely); and (b) I intend to participate in this physical activity intervention on a regular basis; 1 strongly agree - 7 strongly disagree.

\section{Attendance behaviour}

Attendance to 3-month intervention was registered by the physical activity instructor. Attendance was calculated as the number of sessions attended divided the number of sessions expected based on prior agreement for a minimum of two to three sessions per week during the 12 weeks physical activity intervention.

\section{Data analysis}

Data were analysed using the IBM SPSS Statistics ver. 26.0 (IBM Co., Armonk, NY, USA). There was no missing data from the data file. Descriptive statistics were used to present means and standard deviations of all TPB factors. A reliability coefficient (Cronbach alpha) for each of the TPB constructs based on the average covariance among items included in the questionnaire was calculated (Cronbach alpha) to measure internal reliability. Criterion for statistical significance was $P<0.05$, 2-tailed.

Convergent and discriminant validity of the measurements were tested by demonstrating the correlations between the items. Correlation was measured by a correlation coefficient (Pearson correlation) indicating the extent items are linearly related. The hypothesis that each item will reflect its own construct was examined (see Table 1), providing support for the construct validity of this study (Golicic et al., 2012).

Based on the TPB (Ajzen, 1991), the hypothesized model proposed a direct relationship between predictor variables attitude, $\mathrm{SN}$ and $\mathrm{PBC}$, and the outcome variable intention to participate in a physical activity intervention. The relationship between predictor variables and outcome variables (Fig. 1) was tested through a multiple linear regression analysis. Further, multiple linear regression was used to explain the strength of the effect that attitude, $\mathrm{SN}$, and $\mathrm{PBC}$ have in predicting intention to participate in a physical activity intervention. In addition, multiple linear regression analysis was used to explore the relationship of $\mathrm{PBC}$ and intention to participate in predicting attendance behaviour.

Post hoc power analysis was conducted using the G-power 3.1 program (Faul et al., 2009). As baseline, a sample size of 18 and 1 predictor was used for the statistical power. The alpha level for the analysis was 0.05 , being the effect size of $d=0.50$. The effect size of $d=0.50$ was used based on a recent meta-analysis on the associations of the TPB constructs and behaviour (Steinmetz et al., 2016) which is a medium-large effect size (Cohen, 1992). The post boc analyses revealed the statistical power for this study was 0.80 . A total of 18 participants were selected to participated in this study, and 13 had full data for the variables included in the regression model. Low power decreases the sensitive to detect an effect of the predictor variables on the outcome (Button et al., 2013). For linear regression analysis the sample size $(\mathrm{N}=13)$ was under the optimal level $(\mathrm{N}>25)$ but above the minimum $(\mathrm{N}>8)$ required to test the model through a linear regression analysis (Jenkins and Quintana-Ascencio, 2020). Adjusted R-square was used as a coefficient of determination reflecting the proportion of variation in the dependent variable accounted for by the independent variables. The adjusted R-square provides an adjustment to R-square based on the sample size. Test of assumptions of normality through the exam of a predicted probability plot and the Kolmogorov-Smirnov test, homoscedasticity by examining equal distribution of the data in the scatterplot was conducted. The Kolmogorov-Smirnov test revealed the violation of the assumption of normality for the TPB constructs. Transformation of the data has not been recommended (Bishara and Hittner, 2012) therefore, transformation of the data

Table 1. Correlation matrix among theory of planned behaviour variables

\begin{tabular}{lcccc}
\hline Variable & Attitude & Subjective norm & Perceived behavioural control & Intention \\
\hline Attitude & 1 & & & \\
Subjective norm & $0.444(-0.45$ to 0.93$)$ & 1 & 1 & \\
Perceived behavioural control & $0.273(-0.21$ to 0.89$)$ & $0.079(-0.33$ to 0.77$)$ & $0.258(-0.18$ to 0.77$)$ & 1 \\
Intention & $0.456(-0.04$ to 0.90$)$ & $0.912^{* *}(0.66-0.97)$ & $-0.587(-0.95$ to 0.49$)$ & $0.009(-0.36$ to 0.36$)$ \\
Attendance & $0.394(-0.36$ to 0.77$)$ & $0.242(-0.31$ to 0.77$)$ & 1 \\
\hline
\end{tabular}

Values in parentheses indicate the $95 \%$ bootstrap confidence interval for each correlation. $P$-value is reputed to be $>0.05$ if the confidence interval included 0 . The confidence interval is a plausible range of population correlations that could have caused the sample correlation (Cumming, 2014).

** Correlation is significant at the 0.01 level (2-tailed). 
Table 2. Descriptive statistics and Cronbach alpha values of attitude, subjective norm, perceived behavioural control, and intention

\begin{tabular}{lcccc}
\hline Variable & Number & No. of items & Mean \pm SD & Cronbach alpha \\
\hline Attitude & 13 & 2 & $2.03 \pm 1.14$ & 0.763 \\
Subjective norm & 13 & 2 & $1.53 \pm 0.77$ & 0.872 \\
Perceived behavioural control & 13 & 2 & $1.76 \pm 0.83$ & 0.796 \\
Intention & 13 & 2 & $1.57 \pm 0.67$ & 0.865 \\
\hline
\end{tabular}

Attitude, subjective norms, perceived control, and intention measured on a scale from 1 to 7 with lower numbers indicating more positive attitude and norms, higher perceptions of control and intention.

$\mathrm{SD}$, standard deviation.

was not applied. In addition, outliers were kept in analyses, presumed as representing true participant responses. The analysis used nonparametric bias-corrected confidence intervals to assess the significance of the model (Efron, 1987). The regression analysis was performed with 2000 bootstrap replications. Bootstrapping is an approach with advantages over traditional parametric approaches since does not depend on normal and symmetrical sampling distribution (Preacher and Hayes, 2004). Regression parameters and bootstrapped coefficients with $95 \%$ confidence intervals were calculated. The $P$-value was reputed to be $>0.05$ if the confidence interval included 0 . Further, and absence of multicollinearity by examining the variance inflation factor (VIF) were tested. VIF assessment is important in evaluating the independence among the predictor variables, thus the quality of the regression model. The presence of multicollinearity has the potential to impact regression results and its interpretation (Kim, 2019).

\section{RESULTS}

Kolmogorov-Smirnov test indicates that for most of the data measured for attitude distance (D) (13) $=0.206, P=0.136, \mathrm{SN} D$ $(13)=0.295, P=0.003, \operatorname{PBC} \mathrm{D}(13)=0.237, P=0.044$ and intention $\mathrm{D}(13)=0.266, P=0.012$ were not normally distributed. The means and standard deviations are presented for each of the TPB constructs in Table 2. The attitude, SN, PBC, and intention scales each had a Cronbach alpha $>0.76$. These findings indicated that all scales were reliable.

Table 3 confirms convergent correlations are higher than discriminant ones, providing support for the construct validity (Golicic et al., 2012). The loadings of each of the items measuring SN, PBC, and attitude on the constructs they were intended to measure were higher than the loading on constructs that were not planned to measure (Golicic et al., 2012).

Pearson correlations from a bootstrap were calculated between
Table 3. Convergent and discriminant validity of the theory of planned behaviour constructs.

\begin{tabular}{lcccc}
\hline Variable & Attitude & $\begin{array}{c}\text { Subjective } \\
\text { norm }\end{array}$ & $\begin{array}{c}\text { Perceived } \\
\text { behavioural control }\end{array}$ & Intention \\
\hline Attitude 1 & $0.877^{* *}$ & 0.412 & 0.329 & 0.475 \\
Attitude 2 & $0.959^{* *}$ & 0.412 & 0.208 & 0.393 \\
Subjective norm 1 & 0.471 & $0.938^{* *}$ & -0.018 & $0.758^{* *}$ \\
$\begin{array}{l}\text { Subjective norm 2 } \\
\text { Perceived behavioural }\end{array}$ & 0.393 & $0.971^{* *}$ & 0.140 & $0.953^{* *}$ \\
$\quad$ control 1 & -0.057 & $0.902^{* *}$ & 0.011 \\
$\begin{array}{l}\text { Perceived behavioural } \\
\text { control 2 }\end{array}$ & 0.242 & 0.189 & $0.922^{* *}$ & 0.437 \\
Intention 1 & 0.413 & $0.774^{* *}$ & 0.361 & $0.931^{* *}$ \\
Intention 2 & 0.444 & $0.931^{* *}$ & 0.144 & $0.952^{* *}$ \\
\hline
\end{tabular}

${ }^{* *}$ Correlation is significant at the 0.01 level (2-tailed).

the factors (attitude, subj. norms, and PBC), intention, and attendance behaviour. The matrix of correlation coefficients is shown in Table 1 . SN were significantly correlated with intention $(r=0.912$, $P<0.01 ; \mathrm{BCa}$ (bias-corrected and accelerated) 95\% [0.660$0.975])$. Intention and $\mathrm{PBC}$ were not found significantly correlated with attendance behaviour.

In addition, Person correlations between all factors were performed to explore potential collinearity (Mason and Perreault, 1991) (Table 1). Furthermore, attitude, SN, and PBC did not exhibit a high VIF score (i.e., > 5-10) (Craney and Surles, 2002). VIF was used as a multicollinearity diagnostic indicating no multicollinearity problem for the data (attitude scores, tolerance $=0.74, \mathrm{VIF}=$ 1.33 ; $\mathrm{SN}$ scores, tolerance $=0.80, \mathrm{VIF}=1.24 ; \mathrm{PBC}$ scores, tolerance $=0.80, \mathrm{VIF}=1.08$ ). Further, from the scatterplot of standardised predicted values, the data met the assumptions of homogeneity of variance and linearity.

\section{Prediction of physical activity intention}

Attitude and PBC were excluded from the regression analysis because of the lack of significant correlation with intention to participate in the physical activity intervention. Thus, a linear regression analysis was used to predict intention with $\mathrm{SN}$ as independent variable. $\mathrm{SN}$ was able to explain $83 \%$ of the variance in intention $(\beta=0.79, P=0.001)$.

\section{DISCUSSION}

The results of this exploratory study suggest SN as the only significant predictor of intention, accounting for $83 \%$ of variance in intention for Finnish young with CP. The findings of this study 
support the use of the TPB to understand the factors influencing intention in physical activity interventions for youth with CP. This study explored the elements involved in intention and attendance behaviour in a physical activity intervention for Finnish youth with CP. Our study mirrored similar physical interventions applied to youth with $\mathrm{CP}$ that aim to improve physical activity participation (Novak et al., 2013; Stribling and Christy, 2017). Results from this study represent an important step forward to understand the factors influencing intention in physical activity interventions for youth with $\mathrm{CP}$.

\section{Understanding intentions}

From the results, TPB offered excellent prediction of intention towards the physical activity intervention accounting for $83 \%$ of the variance in line with previous studies (Hagger et al., 2002; Norman and Conner, 2005). However, there were discrepancies on the way the attitude, $\mathrm{SN}$, and $\mathrm{PBC}$ contribute to the prediction of intention. This is in concordance with the theory of Ajzen (1991) whereby the impact of the factors depends very much on the context and behaviour. In contrast to previous studies from the general population, where attitudes towards physical activity are the main predictor for intention (Gallagher and Updegraff, 2011; Hagger et al., 2002), the only significant predictor of intention for youth with CP in our study was SN. This finding is in concordance with a recent systematic review pointing $\mathrm{SN}$ as the key factor for youth with disabilities when enrolling in physical activities (Columna et al., 2020), where families or important others would play a key role in promoting physical activity participation (Columna et al., 2019). The results from this study suggest the need for future studies to take subjective experience of the normalised environment into consideration.

In contrast to the previous results from the general population, where $\mathrm{PBC}$ is a strong/moderate predictor of intention (Armitage and Conner 2001; Voon et al., 2011), for Finnish youth with CP $\mathrm{PBC}$ is not a determinant factor on intention to participate in a physical activity intervention. To our knowledge, no previous studies have explored the role of $\mathrm{PBC}$ on intention in youth with CP. Nevertheless, our results are supported by previous studies that found a similar limited role of PBC on intention when participants have limited autonomy over the action (PBC) (Al-Swidi et al., 2014). As it was emphasised in a recent systematic review by Larsson et al. (2018) from the general population, children and youth do not participate or influence the development of interventions targeting their health and well-being. Children and youth are not involved in the goals of the interventions, playing a passive or a "guest" role (Larsson et al., 2018). Children and youth with $\mathrm{CP}$ have a lack of autonomy in healthcare decision-making (Racine et al., 2013). This lack of autonomy or control over the action experienced when participating in a physical activity intervention could explain the limited contribution of $\mathrm{PBC}$ on intention shown in our study. The influence of attitude on intention to participate in a physical activity intervention for Finnish youth with $\mathrm{CP}$ is limited. This result contrasts those from previous literature from the general population where attitude is a key factor in predicting intention to participate in physical activity (Chen, 2007; Poobalan et al., 2012; Voon et al., 2011). As it was emphasised, the limited autonomy over the physical activity intervention could influence the attitude towards such intervention. A positive or negative attitude could have an irrelevant influence on intention to participate in the physical activity intervention. To our knowledge no previous studies have explored the role of attitude towards a physical activity intervention in youth with $\mathrm{CP}$, therefore, future research should explore the role of attitude in such controlled environment and its impact on intention.

\section{Predicting attendance behaviour}

The results contradict the original TPB model by which intention and $\mathrm{PBC}$ have a direct relationship with behaviour. Thus, our results differ from previous literature suggesting that intention to engage in a behaviour is the direct pathway to performing such behaviour (Ajzen, 1991). The results indicate that intention to participate in a physical intervention was not a reliable predictor of attendance behaviour. Intention to participate in a physical intervention was determined by SN. Thus, intention to participate in a physical activity intervention is normatively controlled (Sheeran et al., 1999a). In a normative controlled environment, external pressure (i.e., family, health professional, or peers) have a strong influence on the individuals' intention (Columna et al., 2019). Intention based on $\mathrm{SN}$ is typically less of a reliable predictor for behaviour than, for example, attitudinal intention. Our results are supported by previous studies that have questioned the relationship between intention towards physical activity participation and physical activity behaviour in general population (Chatzisarantis and Hagger, 2005; Sniehotta, 2009). Further, McEachan et al. (2011) pointed the importance of the temporal distance between the measurement of the intention and behaviour. Longer intervals between the assessment of the intention and the record of the behaviour have been suggested as a moderator reducing the predictive validity of intention (Conner et al., 2000). The current study consisted in a 12-week physical activity intervention, the assess- 
ment of the intention was performed previously which could have had a direct impact of the intention-behaviour relationship (Conner et al., 2000; Sheeran et al., 1999b). In addition, the lack of control over the behaviour limits the predictive validity of intention (Kor and Mullan, 2011). In our study, the lack of relation between PBC and attendance behaviour could indicate that the assessment of perceived control was not sufficiently precise to provide an accurate overview of the actual control. However, it could be argued that the nondirect relationship between PBC and behaviour suggests that Finnish youth with $\mathrm{CP}$ had volitional control over the behaviour (Madden et al., 1992). Further research is needed to better understand the PBC-behaviour relationship in youth with CP.

Our study confirms that TPB is a useful instrument to understand better the intention that Finnish youth have towards a physical activity intervention. Further, our results pointed that the questioned relationship intention-behaviour or $\mathrm{PBC}$-behaviour could be limited by some methodological shortcomings barriers, these relationships depend in part of factors beyond the individual's control, in particular the role of the actual control over the attendance behaviour needs of further research.

\section{Study limitations}

Several limitations must be taken into consideration and interpretation of our conclusions are made with some caution. The cross-sectional design has an impact on drawing conclusions about causality of the effects. The relatively small number of participants may represent an important limitation of this study on generalisability of findings. Further, the sample size reduced the statistical power which may have an impact in limiting the significance of some of the statistical processes conducted. Not reaching the $80 \%$ statistical power which implies that small effects could have been not detected. This is a common issue in studies where samples are difficult to recruit (Jenkins and Quintana-Ascencio, 2020). However, this study reached a sufficiently large enough sample to run the regression statistical analysis (Jenkins and Quintana-Ascencio, 2020). Future research including further recruitment and data collection should test our findings. The results are not generalizable beyond youth (9-21 years) with CP classified in GMFS I-III. Other individuals with $\mathrm{CP}$ with greater motor ability restrictions and included in different age groups should be examined to determine if the results also apply to them. In addition, future work should consider the temporal distance between the assessment of intention and the observation of the behaviour when planning an intervention. Finally, future studies might investigate the limita- tions shown in this current study in the predictive utility of the $\mathrm{TPB}$ in individuals with $\mathrm{CP}$.

\section{CONFLICT OF INTEREST}

No potential conflict of interest to this article was reported.

\section{ACKNOWLEDGMENTS}

We thank Mr. Pedro's Valadao for his contributions to the study. The authors received no financial support for this article.

\section{REFERENCES}

Ajzen I. The theory of planned behavior. Organ Behav Hum Decis Process 1991;50:179-211.

Ajzen I, Driver BL. Prediction of leisure participation from behavioral, normative, and control beliefs: an application of the theory of planned behavior. Leisure Sci 1991;13:185-204.

Al-Swidi A, Huque SM, Hafeez MH, Shariff MN. The role of subjective norms in theory of planned behavior in the context of organic food consumption. Brit Food J 2014;116:1561-1580.

Armitage CJ, Conner M. Efficacy of the theory of planned behaviour: a meta-analytic review. Brit J Soc Psychol 2001;40:471-499.

Bélanger-Gravel A, Godin G, Amireault S. A meta-analytic review of the effect of implementation intentions on physical activity. Health Psychol Rev 2013;7:23-54.

Biddle SJ, Ciaccioni S, Thomas G, Vergeer I. Physical activity and mental health in children and adolescents: an updated review of reviews and an analysis of causality. Psychol Sport Exerc 2019;1:146-155.

Bishara AJ, Hittner JB. Testing the significance of a correlation with nonnormal data: comparison of Pearson, Spearman, transformation, and resampling approaches. Psychol Methods 2012;17:399-417.

Button KS, Ioannidis JP, Mokrysz C, Nosek BA, Flint J, Robinson ES, Munafò MR. Power failure: why small sample size undermines the reliability of neuroscience. Nat Rev Neurosci 2013;14:365-376.

Caspersen CJ, Powell KE, Christenson GM. Physical activity, exercise, and physical fitness: definitions and distinctions for health-related research. Public Health Rep 1985;100:126-131.

Chatzisarantis NL, Hagger MS. Effects of a brief intervention based on the theory of planned behavior on leisure-time physical activity participation. J Sport Exercise Psy 2005;27:470-487.

Chen MF. Consumer attitudes and purchase intentions in relation to organic foods in Taiwan: moderating effects of food-related personality traits. Food Qual Prefer 2007;18:1008-1021. 
Chen X, Sekine M, Hamanishi S, Wang H, Gaina A, Yamagami T, Kagamimori S. Lifestyles and health-related quality of life in Japanese school children: a cross-sectional study. Prev Med 2005;40:668-678.

Chevance G, Caudroit J, Romain AJ, Boiché J. The adoption of physical activity and eating behaviors among persons with obesity and in the general population: the role of implicit attitudes within the theory of planned behavior. Psychol Health Med 2017;22:319-324.

Cohen J. A power primer. Psychol Bull 1992;112:155-159.

Columna L, Dillon SR, Dolphin M, Streete DA, Hodge SR, Myers B, Norris ML, McCabe L, Barreira TV, Heffernan KS. Physical activity participation among families of children with visual impairments and blindness. Disabil Rehabil 2019;41:357-365.

Columna L, Prieto L, Elias-Revolledo G, Haegele JA. The perspectives of parents of youth with disabilities toward physical activity: A systematic review. Disabil Health J 2020;13:100851.

Conner M, Sheeran P, Norman P, Armitage CJ. Temporal stability as a moderator of relationships in the theory of planned behaviour. Brit J Soc Psychol 2000;39:469-493.

Craney TA, Surles JG. Model-dependent variance inflation factor cutoff values. Qual Eng 2002;14:391-403.

Cumming G. The new statistics: why and how. Psychol Sci 2014;25:7-29.

Damiano DL. Activity, activity, activity: rethinking our physical therapy approach to cerebral palsy. Phys Ther 2006;86:1534-1540.

Darabi F, Kaveh MH, Majlessi F, Farahani FK, Yaseri M, Shojaeizadeh D. Effect of theory-based intervention to promote physical activity among adolescent girls: a randomized control trial. Electron Physician 2017;9:4238-4247.

de Araújo PA, Starling JM, Oliveira VC, Gontijo AP, Mancini MC. Combining balance-training interventions with other active interventions may enhance effects on postural control in children and adolescents with cerebral palsy: a systematic review and meta-analysis. Braz J Phys Ther 2020;24:295-305.

Drossaert $\mathrm{CH}$, Boer $\mathrm{H}$, Seydel ER. Prospective study on the determinants of repeat attendance and attendance patterns in breast cancer screening using the theory of planned behaviour. Psychol Health 2003;18: 551-565.

Efron B. Better bootstrap confidence intervals. J Am Stat Assoc 1987;82: $171-200$

Faul F, Erdfelder E, Buchner A, Lang AG. Statistical power analyses using $\mathrm{G}^{*}$ Power 3.1: tests for correlations and regression analyses. Behav Res Methods 2009;41:1149-1160.

Fowler EG, Kolobe TH, Damiano DL, Thorpe DE, Morgan DW, Brunstrom JE, Coster WJ, Henderson RC, Pitetti KH, Rimmer JH, Rose J. Promotion of physical fitness and prevention of secondary conditions for children with cerebral palsy: section on pediatrics research summit proceedings. Phys Ther 2007;87:1495-1510.

Gallagher KM, Updegraff JA. When 'fit' leads to fit, and when 'fit' leads to fat: How message framing and intrinsic vs. extrinsic exercise outcomes interact in promoting physical activity. Psychol Health 2011; 26:819-834.

Golicic SL, Fugate BS, Davis DF. Examining market information and brand equity through resource-advantage theory: a carrier perspective. J Bus Logist 2012;33:20-33.

Hagger M, Chatzisarantis N, Biddle S. A meta-analytic review of the theories of reasoned action and planned behavior in physical activity: predictive validity and the contribution of additional variables. J Sport Exercise Psy 2002;24:3-32.

Hawley-Hague H, Horne M, Skelton DA, Todd C. Review of how we should define (and measure) adherence in studies examining older adults' participation in exercise classes. BMJ Open 2016;6:e011560.

Hsu CL, Chang CY, Yansritakul C. Exploring purchase intention of green skincare products using the theory of planned behavior: testing the moderating effects of country of origin and price sensitivity. J Retail Consum Serv 2017;34:145-152.

Jenkins DG, Quintana-Ascencio PF. A solution to minimum sample size for regressions. PloS One 2020;15:e0229345.

Johnson A. Prevalence and characteristics of children with cerebral palsy in Europe. Dev Med Child Neurol 2002;44:633-640.

Kim JH. Multicollinearity and misleading statistical results. Korean J Anesthesiol 2019;72:558-569.

Kolehmainen N, Francis JJ, Ramsay CR, Owen C, McKee L, Ketelaar M, Rosenbaum P. Participation in physical play and leisure: developing a theory- and evidence-based intervention for children with motor impairments. BMC Pediatr 2011;11:100.

Kor K, Mullan BA. Sleep hygiene behaviours: an application of the theory of planned behaviour and the investigation of perceived autonomy support, past behaviour and response inhibition. Psychol Health 2011; 26:1208-1224.

Larsson I, Staland-Nyman C, Svedberg P, Nygren JM, Carlsson M. Children and young people's participation in developing interventions in health and well-being: a scoping review. BMC Health Serv Res 2018; 18:507.

Madden TJ, Ellen PS, Azjen I. A comparison of the theory of planned behaviour and the theory of reasoned action. Pers Soc Psychol B 1992; 18:3-9.

Mason $\mathrm{CH}$, Perreault WD Jr. Collinearity, power, and interpretation of multiple regression analysis. J Marketing Res 1991;28:268-280.

McEachan RR, Conner M, Taylor NJ, Lawton RJ. Prospective prediction of health-related behaviours with the theory of planned behaviour: a meta-analysis. Health Psychol Rev 2011;5:97-144. 
Mulholland E, Van Wersch A. Stigma, sexually transmitted infections and attendance at the GUM Clinic: an exploratory study with implications for the theory of planned behaviour. J Health Psychol 2007;12:17-31.

Neipp MC, Quiles MJ, Leon E, Rodriguez-Marin J. Theory of planned behavior and exercise: deferences between people who do regular physical exercise and those who do not. Wulfenia 2013;20:324-335.

Netemeyer RG, Burton S, Johnston M. A comparison of two models for the prediction of volitional and goal-directed behaviours: a confirmatory analysis approach. Soc Psychol Quart 1991;1:87-100.

Norman P, Conner M. The theory of planned behavior and exercise: evidence for the mediating and moderating roles of planning on intention-behavior relationships. J Sport Exercise Psy 2005;27:488-504.

Novak I, Mcintyre S, Morgan C, Campbell L, Dark L, Morton N, Stumbles E, Wilson SA, Goldsmith S. A systematic review of interventions for children with cerebral palsy: state of the evidence. Dev Med Child Neurol 2013;55:885-910.

Oskoui M, Coutinho F, Dykeman J, Jette N, Pringsheim T. An update on the prevalence of cerebral palsy: a systematic review and meta-analysis. Dev med Child Neurol 2013;55:509-519.

Palisano R, Rosenbaum P, Walter S, Russell D, Wood E, Galuppi B. Development and reliability of a system to classify gross motor function in children with cerebral palsy. Dev Med Child Neurol 1997;39:214223.

Poobalan AS, Aucott LS, Clarke A, Smith WC. Physical activity attitudes, intentions and behaviour among 18-25 years olds: a mixed method study. BMC Public Health 2012;12:640.

Preacher KJ, Hayes AF. SPSS and SAS procedures for estimating indirect effects in simple mediation models. Behav Res Methods Instrum Comput 2004;36:717-731.

Racine E, Larivière-Bastien D, Bell E, Majnemer A, Shevell M. Respect for autonomy in the healthcare context: observations from a qualitative study of young adults with cerebral palsy. Child Care Hlth Dev 2013; 39:873-879.

Ryan JM, Hensey O, McLoughlin B, Lyons A, Gormley J. Reduced moderate-to-vigorous physical activity and increased sedentary behavior are associated with elevated blood pressure values in children with cerebral palsy. Phys Ther 2014;94:1144-1153.

Scalco A, Noventa S, Sartori R, Ceschi A. Predicting organic food consumption: a meta-analytic structural equation model based on the theory of planned behavior. Appetite 2017;112:235-248

Sheeran P, Norman P, Orbell S. Evidence that intentions based on attitudes better predict behaviour than intentions based on subjective norms. Eur J Soc Psychol 1999a;29:403-406.

Sheeran P, Orbell S, Trafimow D. Does the temporal stability of behavioral intentions moderate intention-behavior and past behavior-future behavior relations? Pers Soc Psychol B 1999b;25:724-734.

Sniehotta F. An experimental test of the theory of planned behavior. Appl Psychol-Hlth We 2009;1:257-270.

Steinmetz H, Knappstein M, Ajzen I, Schmidt P, Kabst R. How effective are behavior change interventions based on the theory of planned behavior? Z Psychol 2016;224:216-233.

Stribling K, Christy J. Creative dance practice improves postural control in a child with cerebral palsy. Pediatr Phys Ther 2017;29:365-369.

Valadao P, Piitulainen H, Haapala EA, Parviainen T, Avela J, Finni T. Exercise intervention protocol in children and young adults with cerebral palsy: the effects of strength, flexibility and gait training on physical performance, neuromuscular mechanisms and cardiometabolic risk factors (EXECP). BMC Sports Sci Med Rehabil 2021;13:17.

Verma VK, Chandra B. An application of theory of planned behavior to predict young Indian consumers' green hotel visit intention. J Clean Prod 2018;172:1152-1162.

Verschuren O, Darrah J, Novak I, Ketelaar M, Wiart L. Health-enhancing physical activity in children with cerebral palsy: more of the same is not enough. Phys Ther 2014;94:297-305.

Voon TJ, Ngui KS, Agrawal A. Determinants of willingness to purchase organic food: an exploratory study using structural equation modeling. Int Food Agribus Man 2011;14:103-120.

Wallace LM, Brown KE, Hilton S. Planning for, implementing and assessing the impact of health promotion and behaviour change interventions: a way forward for health psychologists. Health Psychol Rev 2014;8:8-33.

Wang H, Sekine M, Chen X, Yamagami T, Kagamimori S. Lifestyle at 3 years of age and quality of life (QOL) in first-year junior high school students in Japan: results of the Toyama birth cohort study. Qual Life Res 2008;17:257-265.

Wright A, Roberts R, Bowman G, Crettenden A. Barriers and facilitators to physical activity participation for children with physical disability: comparing and contrasting the views of children, young people, and their clinicians. Disabil Rehabil 2019;41:1499-1507.

Zhang X, Geng G, Sun P. Determinants and implications of citizens' environmental complaint in China: integrating theory of planned behavior and norm activation model. J Clean Prod 2017;166:148-156. 